\title{
0 que o doente faz quando fala? A narrativa do doente sob uma perspectiva pragmático-discursiva
} What do the patient do as he/she speaks? Patient's narrative under a discursive-pragmatic perspective

Tatiana PICCARDI

(Universidade Metropolitana de Santos - Unimes)

\section{RESUMO}

O que os doentes, em interação com profissionais de saúde, fazem ao falar? Como se dá a comunicação humana em práticas complexas, como as práticas em saúde? Este artigo pretende refletir sobre essas questões, cooperando para o entendimento da comunicação humana focado na agência dos sujeitos em discurso. Pretende também cooperar para as reflexões sobre a importância da narrativa, não apenas como espaço de agenciamento na prática em pauta, mas também como nova forma de construção de saberes, inclusive cientificos. A perspectiva que permeia toda a reflexão é a pragmática, que entende a linguagem como performativa (Austin, 1975) e lugar por excelência da construção identitária (Rajagopalan, 2006, 2006a, 2003, 2003a).

Palavras-chave: Ato de fala; discurso; narrativa; prática médica. 


\begin{abstract}
When interacting with health professionals, what do sick people do as they speak? How is human communication performed within complex practices such as the ones concerned with health? This paper is aimed at a reflection over these issues to support the understanding about human communication when focused on the agency of subjects within a given discourse. It is also intended to cooperate with the reflection over the importance of narrative not only as a space of intermediation for the practice at issue, but rather as a new way for the construction of knowledge, including scientific knowledge. The perspective that passes through all the parts of the reflection is pragmatics, which understands language as being performative (Austin, 1975) and a place of excellence for the construction of identity (Rajagopalan, 2006, 2006a, 2003, 2003a).
\end{abstract}

Key-words: Speech act; discourse; narrative; medical practice.

\title{
1. Contexto geral da pesquisa
}

Os estudos pragmático-discursivos, em seu conjunto, têm tido por objetivo procurar responder às perguntas: $\mathrm{O}$ que os falantes de fato fazem ao falar? Em que medida e de que maneira suas falas se atrelam às formações sociais e discursivas que permeiam a interlocução? Quais as repercussões dessas falas, tanto no âmbito do contexto imediato, como também no social? Da perspectiva filosófica britânica, tais estudos se sustentam particularmente em Austin $(1975,1993)$ e Wittgenstein (1953). Da perspectiva filosófica denominada continental (em referência aos países do continente europeu, em especial França e Alemanha), as bases estão em pensadores como Foucault (1995, 1996, 2004, 2006), Derrida (1967) e Freud $(1967,1988)$. O que há em comum entre pensadores de locais e épocas relativamente diferentes é que todos eles desconstroem o mito da linguagem neutra e representacional e, de forma mais ou menos explícita, problematizam o sujeito da linguagem e seu papel social, cooperando para que, em anos recentes, os estudos linguísticos recuperassem esse sujeito e o (re)inserissem em seu corpo de preocupações.

Em contextos comunicacionais de complexidade crescente, nos quais o multilinguismo (seja dialetal, seja sociocultural) passa a ser a regra e não a exceção, olhar a linguagem da perspectiva pragmático-dis- 
cursiva pode ajudar a deslocar os sentidos do que seja língua e linguagem e promover as bases para um entendimento da comunicação humana em que a agência do sujeito, imbuído de uma competência não idealizada - ou competência truncada (Blommaert, Collins e Slembrouck, 2005) - passa a ser central. As narrativas de doentes ${ }^{1}$, entendidas como exemplos fortes de extratos comunicacionais em contextos complexos, são o campo linguístico sobre o qual me debruço com o intuito de contribuir para responder às questões em pauta.

Neste artigo, não serão analisadas narrativas específicas. Tendose em vista um conhecimento ainda geral e preliminar do que sejam tais narrativas, o que se pretende é discutir algumas questões teóricas, discussão essa entendida como fundamental para uma correta escolha metodológica e para um levantamento adequado do corpus, que esteja de acordo com o posicionamento crítico/reflexivo ora apresentado. No item 6 , a título de ilustração, apresento um exemplo de narrativa de doente, acompanhado de uma breve reflexão. Uma análise detalhada da íntegra dessa narrativa encontra-se em Carelli et al. (2013).

\section{Contexto teórico}

É ainda bastante difundida a ideia de que a função central da linguagem relaciona-se à possibilidade de ser neutra e objetiva e que, como decorrência, enunciados neutros e objetivos são passíveis de circular nas práticas sociais. Esta ideia, que nasce no bojo de uma filosofia positivista sobre ciência, na qual a linguística se inspirou desde a sua fundação, tem ofuscado um fenômeno inegável, o de que a subjetividade e as emoções estão sempre presentes na linguagem, mesmo que encobertas sob o manto da neutralidade e da objetividade. Esta ideia relaciona-se a outra: a de que existiria linguagem pura. A ciência positiva é a origem e o reflexo dessa noção, ao fazer crer que a linguagem da ciência fala por si. Os discursos médicos atuais são

1. Optou-se neste artigo por usar os termos "doente" e "paciente" (este de modo secundário) para nomear um dos interlocutores do par interlocutivo médico-paciente. Uma breve discussão sobre a dificuldade de realizar tal nomeação de modo adequado está no texto "O Nome do Doente: Poder e Identidade nas Práticas de Saúde no Brasil". 
um exemplo forte deste "fazer crer", perpassando as interlocuções médico-paciente como a materialização da "verdade".

Disciplinas como a sociolinguística, as diversas análises do discurso, a linguística textual, a análise da conversação, as linguísticas da enunciação, a linguística crítica, entre outras (que compõem o núcleo de disciplinas que trabalham a vertente texto-discurso), deram passos importantes no sentido de descentrar tais neutralidade e objetividade, ao deslocar o sujeito falante ideal do centro da cena enunciativa e dar lugar de destaque ao que de modo geral se convencionou chamar de contexto situacional e/ou sócio-histórico. As determinações de caráter social e histórico às quais o sujeito se submete ao falar abalam, em termos teóricos, a possibilidade linguística de ser neutro e objetivo, na medida em que o sujeito só pode falar de um lugar pré-determinado e que as "intenções" que regeriam sua fala estão calcadas não em sua vontade de expressar, mas em coerções sociais que o impelem a falar o que é preciso.

Tais disciplinas nasceram em contextos históricos em que o estruturalismo estrito que fundamentou epistemológica e metodologicamente a linguística desde o seu início começava a ser "desconstruído" (décadas de 50 a 70) nos países centrais produtores de conhecimento na área, em especial França e Inglaterra. No entanto, mantêm-se estruturalistas no sentido amplo do termo, na medida em que preservam a distinção tradicional sujeito-objeto (sujeito falante e linguagem), com a diferença fundamental de que o sujeito falante passa a ser visto como determinado. A determinação social e histórica do sujeito, no entanto, não dá conta de compreender os efeitos de imprevisibilidade das falas e seu caráter performativo e mobilizador, em especial em contextos críticos, como os que envolvem saúde/doença. Nesses contextos, observa-se o apagamento da distinção tradicional sujeito-objeto, na medida em que, para articular e fazer valer uma posição em meio à diversidade, o sujeito de linguagem a toma por inteiro, nela se imiscui, vivencia-a em sua corporalidade, de modo que aquilo que enuncia é aquilo que o sujeito precisa construir de si: a sua verdade.

Compreende-se que é necessário articular de modo mais vivencial a subjetividade e a emoção desse sujeito em ato nas práticas sociais (que sempre envolvem linguagem), de modo a se buscar uma redefinição do que seja língua e linguagem, que tenha como preocupação um melhor entendimento dos fenômenos comunicacionais em contextos nos quais 
a emoção é forte e a vivência corporal determinante. Parto do princípio de que a pragmática social, vertente que priorizo (cf. Mey, 2001, 2001a, 1985; Rajagopalan, 2006, 2006a, 2003, 2003a) - e que entende a linguagem como fundamentalmente ancorada no social, ao mesmo tempo em que assume o papel fundamental da agência do sujeito em discurso - é base teórica produtiva para avançarmos nessa direção, em diálogo com outras disciplinas linguísticas de perfil sociointeracionista e textual-discursivo.

$\mathrm{Na}$ esteira dessas reflexões, os estudos atuais do que aqui denominamos pragmática social abrem as portas para se repensar não apenas o papel da disciplina e seu escopo, mas o papel do linguista que atua a partir das noções propostas pela teoria (e com ela contribui). Vislumbrase a possibilidade de se pensar numa linguística mais interventora, e não apenas criticamente descritiva, ao mesmo tempo em que se pode pensar numa atuação do linguista mais engajada socialmente, e assim mais de acordo com a teoria que sustenta sua prática.

Nessa linha de reflexão, algumas questões centrais acabam por se impor:

1. Como a linguística, ou os estudos da linguagem em seu conjunto, podem ampliar seu escopo, de modo a incluir o sujeito falante (que é socialmente inserido e que tem um corpo que participa do esforço de comunicar) como o seu "objeto" privilegiado de estudos?

2. Como a irredutível interdisciplinaridade resultante desse tipo de abordagem pode ser articulada de modo a manter a especificidade de um estudo linguístico-discursivo? E mais: será essa especificidade necessária?

3. Se o objeto da pesquisa é o sujeito falante de carne e osso, como articular nas pesquisas sua realidade contingencial, suas idiossincrasias e sofrimento? Se a opção for por sua inclusão, como pode o pesquisador se eximir eticamente de uma postura compromissada com esse sujeito? Seria a postura mais compromissada uma exigência de pesquisa, dentro de um novo paradigma científico emergente? Estaríamos então falando de uma linguística interventora? E o que seria isso?

O caminho escolhido em busca de respostas tem sido a análise de narrativas de doentes, empreendimento que apenas se inicia. 


\section{O que são, afinal, as narrativas de doentes?}

São frequentes os relatos de pessoas doentes que dizem ter encontrado alívio para a dor e o sofrimento no ato de narrar a própria história ${ }^{2}$. São também frequentes os casos em que, após um evento traumático, a narrativa surge como o lenitivo mais acessível e democrático, na medida em que, com lápis e papel em mãos, qualquer pessoa, desde que minimamente alfabetizada - e agora na posição de autora! -, ou mesmo por meio do relato oral - desde que haja um interlocutor empático - pode dar vazão à mistura de emoções e sentimentos que percorre o corpo de modo difuso e que aos poucos toma a forma de palavras.

Nesses casos, a narrativa parece ser bem mais do que uma possibilidade estrutural da linguagem, parece ser um fenômeno estruturante, que garante expressão coerente e significativa em contextos nos quais o domínio da linguagem, num estranho paradoxo, não é pré-requisito. $\mathrm{Ou}, \mathrm{em}$ outras palavras, em contextos nos quais a linguagem deixa de ser o lugar privilegiado de construção do sentido e cede lugar ao corpo doente - ou ferido - que, inteiro, fala.

A hipótese que levanto, tendo em vista as experiências pessoais como ouvinte e como autora de histórias de doenças, é a de que a doença, no processo de narrar, pode deixar de ser o referente observável nos textos, o "ele" ao qual "eu" e "tu" apontam, e passa a ser elemento constitutivo do sujeito que enuncia, referente vivido no corpo, numa estranha simbiose que pode dar margem à construção de um sentido positivo para a dolorosa experiência. Por outro lado, a

2. O contato que tenho com os relatos de doentes advém de minha experiência como voluntária na AHPAS - Associação Helena Piccardi de Andrade Silva, instituição de apoio a crianças e adolescentes em tratamento de câncer. No dia-a-dia, histórias de vida desses jovens e familiares se misturam à sua experiência com a doença e o tratamento. Desse material ainda em fase de levantamento e organização nascem as primeiras observações sobre essa valiosa materialidade linguística. Uma de minhas orientandas de iniciação científica, em projeto finalizado na Escola de Filosofia, Letras e Ciências Humanas da Universidade Federal de São Paulo, apoiado pela Fundação de Amparo à Pesquisa do Estado de São Paulo (FAPESP), realizou um levantamento importante dessas narrativas em sua pesquisa intitulada "O uso da linguagem em contextos de saúde/doença: de que maneira a linguagem afeta os interlocutores?”. Dois artigos de minha autoria são significativos para que se inicie a compreensão dos relatos de doentes, uma vez que analisam relatos de dor em contextos de fragilidade. Ambos estão citados nas referências bibliográficas (Piccardi, 2008 e 2013). 
narrativa que mantém o "ele"/doença externo ao sujeito que fala - o que eventualmente ocorre em todo ou apenas em parte do processo de narrar - pode distanciar o sujeito da experiência da doença e dificultar o tratamento.

Pretende-se avaliar em que medida o primeiro modo de articulação do texto narrativo ajuda a tornar mais assimilável, para o paciente, o processo de adoecer/curar e em que medida essa assimilação coopera para o tratamento. Entende-se que o distanciamento provocado pelo segundo modo de articulação da narrativa não leva necessariamente a dificuldades maiores de assimilação da doença e enfrentamento do tratamento. Não se pode estabelecer uma relação direta entre o modo de articulação da narrativa e o modo como se dá o adoecer, sendo, às vezes, o distanciamento e a não-identificação com a doença, atestado pelo modo de narrar, o melhor recurso para sustentar o sujeito durante sua experiência de sofrimento.

Por outro lado, há as narrativas dos médicos, camufladas em falas objetivas atreladas ao discurso médico e à correlata prática profissional. Ambas (narrativa do doente e narrativa do médico) constituem-se como a metáfora viva da dicotomia construída socialmente (ou melhor, pelas disciplinas científicas que estudam linguagem e que são consideradas as instâncias legítimas para alinhavar conceitos e definições autorizadas) que distingue o discurso argumentativo (e racional) do discurso narrativo (e emocional), numa oposição que não se sustenta. Tipo textual argumentativo e tipo textual narrativo só se distinguem de uma perspectiva puramente estruturalista, que desconsidera o enunciado como ato de fala que produz consequências bastante concretas.

Rajagopalan, em prefácio escrito ao meu último livro (Piccardi, 2012: 11), esclarece que

A oposição entre os dois modos discursivos, entre os dois gêneros, remonta os gregos antigos. No mundo austero da academia, acostumamo-nos com grandes tratados-teses hermeticamente fechadas e amarradas que expõem pensamentos rigorosamente arregimentados e cuidadosamente passados pelo crivo de exame minucioso. Nesse mundo, as narrativas são menosprezadas por serem episódicas e quase sempre espontâneas, fruto, muitas vezes, de uma explosão emocional. A preocupação constante no discurso acadêmico é sempre suprimir as emoções e os sentimentos que, segundo a velha cartilha, só servem para 
despistar as atenções e desviá-las do caminho da razão. O intelectual, o acadêmico que se preze, deve seguir o exemplo do Ulisses, herói da epopeia grega, e tapar seus ouvidos diante do canto sedutor da sirene, a figura mítica que encarna emoção, para não perder seu rumo em direção ao seu reino da razão, a Ítaca.

Tal qual o herói grego, o médico, "heroicamente", ignora a narrativa do doente em nome da razão, o que significa ignorar um conhecimento importante que emerge dessas narrativas. Muitas vezes é nelas que se encontra o conhecimento fundamental para que se determine a melhor forma de encaminhar o tratamento.

Consideramos que a distinção dicotômica, na medida em que inibe ao médico a possibilidade de levar em conta a emoção e elementos representativos de dada individualidade que não se esgotam no domínio da razão, impede-o de explorar o que poderia e, a pretexto de garantir o rigor, deixa de lado, muitas vezes, o que é substancial naquela dada circunstância.

Ayres (2004), ao relatar o impasse em que se encontrou diante de uma paciente que se negava a entrar no domínio da "razão médica" e não atendia aos prescritos, nos mostra a importância de incorporar a narrativa do doente à prática interlocutiva em consulta. Observe-se que não se trata apenas de incorporar a narrativa do doente para viabilizar ao paciente, por meio de uma linguagem que domina, os meio de acatar um certo diagnóstico e um certo tratamento. Trata-se de promover uma ruptura epistemológica que eleva a narrativa corriqueira, e às vezes fragmentada e aparentemente incoerente, ao lugar de produção de um saber que não pode ser desprezado e ao qual o médico deve responder à altura, deslocando-se da racionalidade médica expressa na linguagem pretensamente objetiva e especializada para o desconcertante campo da linguagem do corpo que se emociona, é forte e frágil ao mesmo tempo, esforça-se por imprimir sentido e coerência à experiência e se nega a descartar essa experiência do conjunto dos saberes necessários à sua própria cura.

\section{O narrative turn nas ciências sociais e humanas}

De Fina e Georgakopoulou (2012: ix), em sua tentativa (não exaustiva) de rastrear os diferentes sentidos de narrativa nas ciências sociais 
e humanas e apontar para o significado da importância crescente do estudo da narrativa, nos dizem, no Prefácio ao livro:

We both felt that, although scholars from sociolinguistcs, discourse analysis, linguistic anthropology, social and discursive psychology, just to name some of the fields covered in this book, had produced a vast body of research and theoretical reflection on narrative, a comprehensive and critical evaluation of their work was lacking. This was with stark contrast to the proliferation of textbooks and resource books that present sociological, cultural studies and literary approaches to narrative. Our aim was to redress the balance by highlighting the specificities of a language and discourse-focused perspective on narrative but also its important place within the narrative turn in the social sciences. (meu grifo)

Independentemente do que se possa pensar a respeito da proliferação de abordagens e sua coerência, uma coisa é certa: se a narrativa está em foco, é porque a racionalidade em senso estrito não dá mais conta de compreender determinados fenômenos da vida social. Os pesquisadores estão sentindo isso na pele - que finalmente reconhecem possuir -, e entendem, ou começam a entender, sua imbricação pessoal e afetiva com os fenômenos que pesquisam. Ao pesquisar, também contam uma história, sua história...

A prática médica caminha na mesma direção. A narrativa do paciente aos poucos deixa de ser ignorada. Aos poucos, também, a fala objetiva do médico passa pelo seu próprio crivo (Cf. Ayres, 2004). Esta se desnuda como um lugar ao mesmo tempo de dominação do saber médico constituído e lugar de contar a história desse poder, imiscuído à história pessoal e profissional do médico em sua prática.

\section{O narrative turn como o caminho para uma linguística pós-estruturalista}

Ottoni (2002) estabelece uma interessante relação entre a proposta filosófica de Wittgenstein e a de Austin. Embora de modo geral os dois estudiosos se alinhem, na medida em que, inseridos no mesmo contexto histórico, ambos se posicionam criticamente contra os pressupostos em voga na filosofia analítica e abrem as portas para os estudos do que se 
convencionou chamar de linguagem ordinária ${ }^{3}$, a ruptura proposta por Wittgenstein seria ainda neo-moderna, enquanto a de Austin seria pósmoderna, segundo distinção feita por Ruby $(1990)^{4}$. Segundo Ottoni (2002:140), Wittgenstein teria procurado "recuperar uma modernidade inacabada (modernité inachavée), identificando-se com a universalidade e a razão moderna", enquanto Austin teria rompido com uma cultura anterior (a moderna), desarranjando-a. Nessa direção, pode-se dizer que Austin, juntamente com outros filósofos mais ou menos contemporâneos (como Derrida e Foucault), desconstroem todo um modo de fazer filosofia (o modo da modernidade). Com isso, afetam os estudos da linguagem que nesse modo se assentam e anunciam um modo pós-moderno (e pós-estruturalista) de estudar a linguagem, mais afim com o novo desenho social, caracterizado pela diversidade dos rearranjos intersociais e interculturais.

Alinhado, assim, ao que hoje entendemos por pós-estruturalismo nos estudos linguísticos, para Austin, o sujeito não se afasta do objeto linguagem. De fato, a ideia de afastamento é em si uma abstração estruturalista, pois o que se observa é que o ato de fala é indissociável do ato de realizar uma ação ao falar; ou, dito de outro modo, o sujeito é indissociável da linguagem que produz, e esta está imiscuída no social, nele se mistura e dele se constitui. $\mathrm{O}$ ato de fala se dá num mundo palpável e contingencial, em que a corporalidade está presente e as intenções se transformam em força ilocucionária e efeitos perlocucionários que só existem enquanto tais porque há sujeitos concretos, que buscam na e pela linguagem marcar posições, defender interesses e consolidar identidades.

É assim que Austin entende o ato de fala como eminentemente performativo, em oposição ao que se conhece por enunciado constativo, ou declarativo (outra abstração fruto da modernidade, a qual Austin combate firmemente).

Desta forma, o desafio central de uma linguística pós-estruturalista, como estamos chamando os estudos desenvolvidos por uma pragmática

3. Rajagopalan (2009) traça um breve e excelente panorama do que seja a filosofia da linguagem ordinária (FLO) e sua repercussão em diferentes disciplinas; posiciona Austin no centro dessa filosofia; e, de certa forma, lamenta a pouca compreensão que a FLO tem tido no interior do que se conhece por linguística propriamente dita (linguistics proper). 4. Ottoni cita Ruby, C. (1990) Le Champ de Bataille-post-moderne/neo-moderne. Paris: Edition l'Harmattan. 
social autoconsciente de seu papel político, é o de identificar, a cada situação de fala, as implicações possíveis da força ilocucionária em jogo e dos possíveis efeitos perlocucionários. Assim é que as noções de ato de fala e de performatividade, tais como desenvolvidas por Austin, são básicas nesta abordagem.

A pragmática social aqui proposta para o estudo da narrativa do doente parte, então, da teoria dos atos de fala de Austin, mas com um diferencial: faz equivaler ato de fala a ato pragmático (Mey, 2001). Isto significa desassociar certas formas linguísticas de certos atos, ou seja, desistir abertamente das associações/classificações que Austin procurou fazer, seguido por Searle. Entende-se que as formas linguísticas que traduzem um certo ato de fala podem variar muito. Mais importante do que distinguir e relacionar um grupo fixo de formas a certos atos é aprender a observar as relações entre forma linguística e ato de fala construídas efetivamente em dada situação e qual ancoragem social dá sentido ao que é enunciado. Daí o uso que faço da expressão pragmático-discursivo, que pressupõe uma compreensão da língua como fato social, gerador/construtor de narrativas.

\section{Um exemplo de narrativa de doente}

Carelli et al. (2013), embora de uma perspectiva um pouco diferente da que se pretende adotar para a análise da narrativa de doentes, nos apresenta a análise de um extrato que é aqui reproduzido para que se observe, de modo preliminar, a constituição e os efeitos desse tipo de narrativa em ato, ou seja, durante a prática interlocutiva com o médico, no ambulatório de um hospital público da cidade de São Paulo.

O trecho se refere a diálogo travado em consulta entre a paciente (uma senhora de 52 anos que sofre de tabagismo) e a médica, após a primeira ter tido de enfrentar dificuldades de diferentes ordens a fim de ajustar-se ao agendamento proposto pelo hospital.

Segue-se o relato:

"Doutora, é o seguinte. Eu já vim aqui uma outra vez, me inscrevi pra fazer o tratamento antitabagismo, assisti palestra, passei no médico, ele me pediu pra fazer uns exames. Tá, eu não tinha como chegar aqui 
às sete horas da manhã pra fazer o exame. Eu tenho plano de saúde. Eu fui na minha médica, pedi pra ela pedir os exames que ele pediu no nome dela pra eu poder fazer pelo plano de saúde. Entendeu? Eu tive que procurar laboratório pelo plano de saúde para não ter que pagar particular, demorou um pouco, eu perdi o dia da consulta. Eu vim aqui no outro dia e falei com a moça lá, que marca, ela marcou, o médico que me atendeu falou que tinha que marcar tudo de novo. Daí eu falei pra ela, ela disse não, magina, vou marcar uma consulta como se fosse a primeira vez, já pensou você ter que se inscrever e esperar assistir palestra, tudo? Eu vou colocar como uma primeira consulta, eu falei, ah, beleza então. Então hoje, tá marcado, eu vim..."

Segundo Carelli et al., "nesse dado momento, há um corte, até certo ponto brusco, da narrativa da paciente, e uma intervenção incisiva da parte da médica". Segue-se a fala da médica e o diálogo subsequente:

"Certo... deixa eu só fazer algumas perguntas pra senhora, dona $\mathrm{P}$, que a senhora passou em uma consulta, né? Que tá registrado aqui no sistema. [...] Hoje o ambulatório é de casos novos, a gente começa desde o início, eu dou uma olhada nos seus exames, a gente pergunta tudo de novo, eu vejo direitinho os medicamentos que a senhora tá tomando.

Mas os exames vão servir, os que eu trouxe, né?

Eu vou dar uma olhada. A senhora tá com cinquenta e dois anos, né?

Isso.

A senhora nasceu aonde?

Salvador, Bahia.

Mora em São Paulo?

Moro.

Faz quanto tempo?

Trinta anos.

A senhora trabalha ainda?

Trabalho.

No quê?

Eu sou... artesã.

A senhora é casada?

Sou.

Tem quantos filhos?

Uma de vinte e seis anos.

E a senhora procurou aqui o ambulatório da clínica pra tentar parar de fumar $[\ldots] "$ 
O que cabe inicialmente observar no primeiro trecho é que, de modo um tanto confuso e atabalhoado, a paciente procura expor mais do que uma queixa. Ela procura, ao enunciar, dar ordem a uma série de eventos da vida diária e imprimir alguma coerência à sua angústia frente a questões bem concretas que afetam o seu dia-a-dia: questões financeiras ligadas a usar ou não o plano de saúde; dúvidas quanto a consultar-se ou não com um médico particular; dificuldade para deslocar-se para o hospital; necessidade de assistir mais uma vez à palestra sobre tabagismo e as dificuldades para atender a essa eventual necessidade etc.

No entanto, a médica, por exigência de profissão e atendendo aos prescritos que seguem uma lógica própria dentro da prática médica, altera o rumo da conversa a fim de que possa extrair as informações que - estas sim - seriam as relevantes para o prosseguimento do tratamento. Para a paciente, no entanto, questões de ordem prática continuam fazendo parte da pauta do diálogo. Ao perguntar: "Mas os exames vão servir, os que eu trouxe, né?", a paciente reage ao redirecionamento da conversa e busca integrar saberes de universos distintos, que precisam ali ser equacionados. A performatividade deste enunciado, portanto, não se reduz ao seu valor de pergunta, mas visa à garantia de que os esforços empreendidos até aquele momento serão validados. A força ilocucionária constrói-se como tentativa de preservar um fazer e um saber nem sempre entendidos como relevantes no discurso médicocientífico.

\section{Considerações finais: base filosófica para continuar a conversa...}

Anéas e Ayres (2011: 652), ao problematizarem a importância da narrativa nas práticas de saúde, ressaltam a necessidade de se deslocar o eixo da consulta médica do abstrato universo da generalização científica e conceitos correspondentes para o mundo humano e palpável da contingência, seja ela vivida no corpo em função da doença, seja ela a contingência social e situada que leva os falantes a enunciarem o que enunciam durante a interlocução: 
O ato médico fundado no cuidado é sempre uma interação entre duas pessoas. Porém, a operação técnica aparece, muitas vezes, separada da relação interpessoal. Mesmo a interação é dividida na relação com o outro, que se consolida apenas com a finalidade da obtenção de informações objetivas, em que se busca o que é relevante para o raciocínio clínico para assim estabelecer uma boa decisão assistencial. A interação se resume a uma conversa que é útil.

Para os autores, a "conversa útil” é aquela que é útil para o médico no exercício da função. Exclui qualquer forma de interlocução que possa tornar visível ou palpável o que o prescrito ignora ou exclui, ou seja, a narrativa do doente.

Uma perspectiva pragmático-discursiva adequada precisa conter em seus pressupostos filosóficos uma nova ontologia, ou melhor, uma desconstrução ontológica que dê lugar a uma nova ontologia, ou talvez a uma não-ontologia, mais ou menos como a desenvolve o filósofo Heidegger, que relativize os constructos prévios e priorize o aquiagora da interlocução, que implica dar espaço à narrativa do doente $\mathrm{e}$ valorizá-la como lugar legítimo de produção de saberes.

Heidegger nos interessa porque, na contramão do mainstream filosófico ocidental, e a despeito das controvérsias quanto à coerência de seus achados, a filosofia, para ele, nasce da necessidade de o filósofo afinar-se com, co-responder-se com o Ser do ente, buscando relação harmônica com o Ser que, por sua vez, desnuda-se ao promover o constante apelo à sua existência. O filósofo realiza seu feito se estiver disposto a "ouvir" o Ser do ente, mantendo-se em estado de constante espanto diante do mundo. Esse modo de fazer filosofia é profundamente dialógico, não estável, e dilui as distinções entre o sujeito que filosofa, o mundo sobre o qual filosofa e o saber decorrente de seu pensar o mundo. A filosofia passa a ser fundamentalmente uma troca dialógica, processo em que o homem é simplesmente ouvinte e respondente privilegiado da existência.

Em franca oposição a Descartes, para Heidegger não é a apreensão da permanência que caracterizará o Ser. Heidegger entende que a impermanência é constitutiva do Ser, não o contrário, e negá-la é ser incapaz de apreender a realidade do Ser. O entendimento da imperma- 
nência decorre justamente desse modo dialógico de fazer filosofia, em si mesmo em constante movimento. De modo contundente, Heidegger (2009: 148) desqualifica o "ser" cartesiano ao dizer que

Descartes não retira o modo de ser dos entes intramundanos deles mesmos. Com base numa ideia de ser, velada em sua origem e não demonstrada em sua legitimidade (ser = constância do ser simplesmente dado), ele prescreve ao mundo o seu ser "próprio". Não é, portanto, principalmente o apoiar-se numa ciência particular e, por acaso, especialmente estimada, a matemática, o que determina a ontologia do mundo, mas uma orientação fundamentalmente ontológica pelo ser enquanto constância do ser simplesmente dado, cuja apreensão é lograda, de modo excepcional, pelo conhecimento matemático.

É a rigidez dos fundamentos cartesianos que dá base a distinções caras à filosofia ocidental como mente $v s$ corpo, razão $v s$ emoção, descrição/argumentação $v s$ narração, ciência $v s$ arte. Como se sabe, a ciência (incluímos aqui a medicina e, mais adiante no tempo, a linguística) se constrói sobre o paradigma dicotômico cartesiano. O desenvolvimento da ciência cartesiana e positiva foi estrondoso, mas, calcado exclusivamente nos primeiros termos dos binômios acima, deixou muito de lado. É nesse sentido que a perspectiva heideggeriana nos interessa, pois nos permite pensar além dos binômios mencionados. Permite-nos averiguar em que medida corpo, emoção, narração, como fenômenos integrantes da existência, são espaços de construção de um saber que, por um novo viés epistemológico, poderia ser considerado científico. Evidentemente o entendimento do que seja ciência se altera. Na prática médica, o saber legítimo se desloca do médico, a narrativa do paciente ganha espaço, novas indagações são formuladas e consequências não previstas ainda estão por ser avaliadas.

Estamos finalizando o texto a as perguntas enunciadas acima permanecem prenhes de respostas. Pouco veio à luz, exceto, talvez, a percepção de que a narrativa do doente faz mais do que aparenta fazer. É capaz de, mesmo sem ter sido devidamente explicitada, induzir à formulação de um artigo como este, que está longe de se esgotar aqui.

Recebido em novembro de 2013

Aprovado em fevereiro de 2015

E-mail: tpiccardi@gmail.com 


\section{Referências bibliográficas}

AnÉAs, Tatiana; Ayers, José Ricardo. 2011. Significados e sentidos das práticas de saúde: a ontologia fundamental e a reconstrução do cuidado em saúde. Interface Comunicação Saúde Educação, v.15, n. 38, 651-62.

Austin, John Langshaw. 1975. How to do things with words. $2^{\text {nd }}$ ed., Cambridge/Massachusetts: Harvard University Press.

1993. Sentido e percepção. Trad. Armando Manuel Moura de Oliveira. São Paulo: Martins Fontes.

Ayres, José Ricardo. 2004. O cuidado, os modos de ser (do) humano e as práticas de saúde. Saúde e Sociedade, v.13, n.3, p.16-29.

Blommaert, Jan; Collins, James; Slembrouck, Stef. 2005. Spaces of multilingualism. Language \& Communication, n. 25, p. 197-216.

Carelli, Fabiana; Lens, Andréa; Oliveira, Amanda; Santos, Ariadne; Reis, Mariluz dos; Pompilio, Carlos Eduardo. 2013. Hidra de duas cabeças: configuração ricoeuriana e narrador impuro numa narrativa do HC-FMUSP. Revista Internacional de Humanidades Médicas.

Derrida, Jacques. 1967. De la grammatologie. Paris: Éd. de Minuit.

De Fina, Anna; Georgakopoulou, Alexandra. 2012. Analyzing Narrative. Discourse and Sociolinguistic Perspectives. New York/Cambridge: Cambridge University Press.

Foucault, Michel. 2006. O nascimento da clínica. $6^{\mathrm{a}}$. ed., trad. Roberto Machado. Rio de Janeiro: Forense. . 2004. Microfísica do poder. 19.ed. (org. e trad.) Roberto Machado. Rio de Janeiro: Graal. . 1996. A ordem do discurso. Trad. Laura F. de Almeida Sampaio. São Paulo: Loyola. . 1995. A arqueologia do saber. 4. ed., trad. L.F. Baeta Neves. Rio de Janeiro: Forense.

Freud, Sigmund. 1988. Le mot d'esprit et sa relation à l'inconscient. Paris: Gallimard. . 1967. L'interpretation dês rêves. Paris: PUF.

HeIDEgGer, Martin. 2009. Ser e tempo. $4^{\mathrm{a}}$ ed.Trad. e apresentação Marcia Sá Cavalcante Schuback. Petrópolis: Vozes.

Otтoni, Paulo. 2002. John Langshaw Austin e a visão performativa da linguagem. D.E.L.T.A. 18:1, 117-143.

PiCCARDI, Tatiana. 2013. Estilo e autoria em relatos de dor. Matraga Estudos Linguísticos e Literários. v. 20, n 32, 221-238. 2012. A atividade do voluntário no mundo do trabalho: construção de um novo perfil. São Paulo: Annablume / Fapesp. 
2008. Relatos de pais enlutados: a dor posta em discurso. Revista Alpha (Patos de Minas), ano 9, n. 9, 129-137.

Rajagopalan, Kanavillil. 2009. Ordinary language philosophy. In Key ideas in Linguistics and the Philosophy of Language. Org. Siobhan Chapman e Christopher Rouledge. Edinburgh University Press, 149-155.

. 2006. Pós-modernidade e a política da identidade. In K. Rajagopalan e D.M.M. Ferreira (orgs.), Políticas em linguagem: perspectivas identitárias. São Paulo: Mackenzie.

. 2006a. Social aspects of pragmatics. In Encyclopedia of Language and Linguistics. Vol. on Pragmatics. Org. Jacob Mey. Reino Unido: Elsevier.

2003. Por uma lingüística crítica: linguagem, identidade e a questão ética. São Paulo: Parábola.

. 2003a. The philosophy of applied linguistics. In Davies, A. e Elder, C. (orgs.), Handbook of applied linguistics. EUA: Blackwell.

Wittgenstein, Ludwig. 1953. Philosophical investigations. Translated by G.E.M. Anscombre. New York: The MacMillan Co. 